\title{
APERTURAS Y LIMITACIONES DE LA TRANSFORMACIÓN DE LA CULTURA POLÍTICA JUVENIL A PARTIR DE UN PROCESO DE FORMACIÓN CIUDADANA ${ }^{1}$
}

\author{
OMAIRA CATHERINE ARBoleda VelÁSQUEZ ${ }^{2}$ \\ BEATRIZ ELENA GARCÍA CHACÓN ${ }^{3}$ \\ ANA LUCÍA PUERTA RENDÓN ${ }^{4}$ \\ SANTIAGO Alberto MORALEs MesA ${ }^{5}$
}

\begin{abstract}
RESUMEN
El artículo aborda cómo un proceso formativo para la participación ciudadana incide en los sentidos, prácticas y transformaciones de la cultura política juvenil local de la ciudad de Medellín, Colombia. Presenta los análisis derivados de una investigación soportada en estrategias metodológicas cualitativas. Los resultados atienden a que el proyecto logra establecer un campo de socialización política en el que los y las jóvenes se sitúan como agentes de transformación de sus territorios mediante el acto formativo que dinamizan y el ejercicio de prácticas políticas que se entretejen con los escenarios de participación local y de expresión juvenil en el que las subjetividades, afectos y estéticas que vivencian desde su condición de juventud resultan determinantes.

PALABRAS CLAVES: CIUDADANÍA JUVENIL, FORMACIÓN CIUDADANA, PARTICIPACIÓN CIUDADANA

\footnotetext{
${ }^{1}$ Los resultados presentados en este artículo se derivan de la investigación desarrollada por la Universidad Católica Luis Amigó y la Alcaldía de Medellín: «Estrategias y propuestas pedagógicas desarrolladas por los jóvenes dinamizadores que hacen parte del proyecto Semilleros Infantiles para la Participación de la Subsecretaría de Formación y Participación Ciudadana de la Alcaldía de Medellín», desarrollado durante 2014 y 2015.

${ }^{2}$ Antropóloga, magíster en Estudios Urbano Regionales y estudiante del Doctorado en Ciencias Sociales de la Universidad de Chile. Correo electrónico: karyve1@gmail.com

3 Trabajadora social y magíster en Ciencias Sociales, investigadora Laboratorio Universitario de Estudios Sociales (LUES), Universidad Católica Luis Amigó, Medellín, Colombia. Correo electrónico: beatrizelena.chacon@gmail.com

${ }^{4}$ Trabajadora social y especialista en Gerencia Social, líder de Programa de la Unidad de Investigación y Extensión, Alcaldía de Medellín, Colombia. Correo electrónico: ana.puerta@medellin.gov.co

${ }^{5}$ Sociólogo y magíster en Salud Pública, docente de la Facultad de Derecho y Ciencias Políticas, Universidad Católica Luis Amigó, Medellín, Colombia. Correo electrónico: smorales@funlam.edu.co
} 


\title{
ABERTURAS E LIMITAÇÕES DA TRANSFORMAÇÃO DA CULTURA POLÍTICA JUVENIL A PARTIR DE UM PROCESSO DE FORMAÇÃO CIDADÃ
}

\begin{abstract}
RESUMO
O artigo aborda como um processo formativo para a participação cidadã afeta os significados, práticas e transformações da cultura política juvenil local da cidade de Medellín, Colômbia. Apresenta as análises derivadas de uma pesquisa sustentada em estratégias metodológicas qualitativas. Os resultados mostram que o projeto consegue estabelecer um campo de socialização política no qual os e as jovens se situam como agentes de transformação de seus territórios através do ato formativo que dinamizam e do exercício de práticas políticas que se entrelaçam com os cenários de participação local e de expressão juvenil onde as subjetividades, os afetos e as estéticas que experimentam a partir de sua condição de juventude resultam determinantes.
\end{abstract}

PALAVRAS-CHAVE: CIDADANIA JUVENIL, FORMAÇÃO CIDADÃ, PARTICIPAÇÃO CIDADÃ

\section{OPENINGS AND LIMITATIONS OF THE TRANSFORMATION OF YOUTH POLITICAL CULTURE FROM A CITIZEN TRAINING PROCESS}

\begin{abstract}
This article addresses how a formative process for citizen participation affects the meanings, practices, and transformations of the local youth political culture in the city of Medellín, Colombia, presenting analyses derived from a research work supported by qualitative methodological strategies. The results show that the project manages to establish a field of political socialization where young male and women are positioned as agents of transformation of their territories through the training act they conduct, and the exercise of political practices that are interwoven with the scenarios of local participation and youth expressions in which the subjectivities, affections, and aesthetics experienced from their condition of youth are crucial.
\end{abstract}

KEYWORDS: YOUTH CITIZENSHIP, CITIZEN TRAINING, CITIZEN PARTICIPATION 


\section{INTRODUCCIÓN}

La cultura política referenciada por un grupo de jóvenes de la ciudad de Medellín y cómo en esta incide un proyecto de formación ciudadana financiado por la administración municipal fue el eje de indagación del proceso investigativo del cual se deriva el presente artículo. En el análisis, se privilegiaron posturas de orden interpretativo dentro del prisma de las tradiciones teóricas y metodológicas que abordan los estudios de la cultura política. Desde este enfoque, se vincularon al análisis nociones de vida cotidiana, prácticas sociales y repertorios de acción que ponen su acento en cómo se configuran los significados culturales tejidos por las personas en su interacción cotidiana con lo político (Lechner, 1994; Heras, 2002) y que, además, permiten develar conceptos, creencias, valores y comportamientos de este grupo de jóvenes en particular, al mismo tiempo que expresan rasgos y condiciones de la cultura política de las juventudes de la ciudad.

La investigación se focalizó en las experiencias y contextos relatados por los y las jóvenes que se integran al proyecto Semilleros Infantiles para la Participación mediante la figura de «dinamizadores» y «dinamizadoras». Este Proyecto (como se nombrará de aquí en adelante) se origina en los años 90, a partir de la iniciativa comunitaria de las Juntas de Acción Comunal (en adelante, JAC $)^{6}$ y el apoyo de la Alcaldía de Medellín (Colombia). Nace con el objeto de promover la participación comunitaria y política como camino para enfrentar la crisis sociopolítica del país y la ciudad, en un período histórico marcado por graves índices de violencia y problemas de orden público ${ }^{7}$, pero también por las

\footnotetext{
${ }^{6}$ Organizaciones sociales de carácter territorial constituidas para la autogestión comunitaria en barrios, veredas y sectores.

${ }^{7}$ Desde 1986 y durante la década del 90 el homicidio se convirtió en la primera causa de mortalidad general en la ciudad de Medellín. Las tasas de mortalidad le otorgaron en este período el reconocimiento como la ciudad más violenta de Colombia y una de las más violentas del mundo (Cardona et al., 2005).
} 
expectativas emanadas de una nueva Constitución Política (1991) que sentaba las bases para la construcción de una democracia participativa. Lo anterior, mediante un proceso formativo en participación ciudadana con enfoque territorial que tiene como beneficiarios finales a niños y niñas de 8 a 12 años, este es impartido anualmente y dinamizado por jóvenes entre los 16 y 25 años que pertenecen a los mismos territorios en los que se desarrolla — barrios y veredas de las comunas y corregimientos municipales-. El número de semilleros anuales puede variar de acuerdo con factores presupuestales, pero, dado que hay un esfuerzo por mantener la continuidad de los niños y las niñas en el proceso formativo, usualmente se realizan alrededor de doscientos.

El Proyecto se estructura a partir de una propuesta pedagógica orientada por la administración municipal, de la cual se derivan los ejes de los contenidos y las metodologías. Estos son adecuados por profesionales sociales vinculados al Proyecto, los cuales en compañía con las dinamizadoras y los dinamizadores elaboran el diseño de las diferentes estrategias pedagógicas y didácticas que tienen los encuentros con niños y niñas, impartidos semanalmente por cuatro horas. El Proyecto contempla simultáneamente a la formación de los niños y las niñas la de las y los jóvenes, de tal forma que participan de un proceso formativo particular coordinado por un equipo técnico de profesionales en pedagogía y ciencias sociales. Este proceso tiene como fin fortalecer la apropiación conceptual y las competencias didácticas de los jóvenes, de acuerdo con las orientaciones de la propuesta pedagógica general.

De esta manera, los dinamizadores y las dinamizadoras son jóvenes que cumplen una doble función en el quehacer pedagógico: sujetos en formación y formadores. Su papel es el de ser promotores o facilitadores de los procesos formativos con los niños y las niñas, lo cual se fundamenta en el reconocimiento de los saberes que tienen de sus territorios como factor estratégico de la participación ciudadana (Brand, 2018). En tal sentido, se identifica que los jóvenes como sujetos de formación se convierten en agentes y que, en su tarea de 
formar a otros, realizan un miramiento de sí mismos y modifican sus respuestas, sus prácticas, sus actitudes y comportamientos; es decir, participan de un escenario de reflexividades que redunda en la configuración de sus subjetividades y el devenir de su cultura política.

La investigación se soportó en una metodología cualitativa. Fueron realizadas entrevistas semiestructuradas, grupos focales y técnicas interactivas que permitieran reconstruir, discutir y reflexionar la praxis social de este grupo de jóvenes, entendida esta «como una unidad compleja y dialéctica formada por la teoría y la práctica» (García, Quiroz y González, 2002: 30). Aunque la vinculación con los espacios formales de participación constituía un eje de interés, la metodología y las preguntas diseñadas abrieron el horizonte de análisis a otros escenarios locales de lo político, en los cuales las juventudes adquirieren especial protagonismo al interpelar y aportar a la ampliación de las fronteras de las políticas públicas juveniles a partir de tránsitos entre la recreación, la resistencia o la reversión de lo establecido, lo cual converge con los resultados de otros estudios en el campo (Vázquez, 2011; Varón, 2014; Henao y Pinilla, 2009; Vecina, 2016).

Se parte de la premisa de que «todo individuo, aún sin reconocerlo, [tiene] un acervo cultural de lo político. Es decir una determinada cultura política, aun haciéndola objetiva o no» (Heras, 2002: 286). Dicho acervo no es otra cosa que la decantación de cómo se comprenden los escenarios políticos en los que se desenvuelven los sujetos y, por tanto, el sustento de la generación y configuración de acciones que responden a dicha comprensión. Todo ello enmarca otras significaciones alrededor de la ciudadanía: el poder, la vida pública y las formas de relacionamiento con el Estado y sus gobernantes, entre otros. Significaciones en constante tensión dadas las disputas de sentido que emergen del encuentro entre lo vivido y lo instituido en el marco de las trayectorias de los jóvenes; lo que alcanza su mayor expresión en formas concretas de participación en las que se profundiza el sentido de ser ciudadano, se desborda el estatus meramente 
jurídico y se expone la posibilidad de emprender acciones de interés o control sobre lo público (Botero, Torres y Alvarado, 2008; Bermúdez, Parra, Patarroyo y Peña, 2013).

En el marco de lo expuesto, la indagación por la cultura política comprendió cuatro ejes analíticos: poder, socialización política, ciudadanía y acción política. Poder, como factor intrínseco de lo político toda vez que determina las posibilidades de relacionamiento y decisión que, tácita o explícitamente, tienen los sujetos en los escenarios colectivos. Socialización política, con el propósito de abordar la incidencia de aspectos de la vida cotidiana y las experiencias de los jóvenes en la construcción de unos sentidos de lo político. Ciudadanía, que permitió indagar en el reconocimiento, las calidades y el ejercicio de derechos y deberes políticos por parte de los miembros que se identifican con una comunidad. Y la acción política, como la práctica y performatividad desde el lente y énfasis de la participación social y ciudadana.

Se reconoce en las formas de participación de las y los jóvenes dinamizadores un sentido de lo político que puede aludir a la reproducción del orden establecido (tanto en lo micro como en lo macro) o a la construcción de nuevos significados que compiten con él. En este punto, se precisa atender a las maneras cómo convergen, diferencian y tensionan las representaciones de lo político y la acción política realmente ejercida; es decir, los sentidos expresados y los repertorios de participación como práctica. Y entender, en este marco, la incidencia de la intervención que tiene el proyecto en ambas dimensiones, para así no solo aportar en la comprensión de la cultura política de los jóvenes de la ciudad, sino además dar luces sobre la capacidad de ser interpelada por procesos de formación ciudadana con jóvenes.

De este tipo de análisis surgen indagaciones más concretas que, además de haber orientado el curso de la investigación, se convierten en la línea discursiva del presente artículo: ¿cuáles son los escenarios locales de la política? 
¿Cómo se conciben y cómo interaccionan las y los jóvenes con ellos? ¿Cómo sus prácticas los recrean, los resisten o los revierten? Y, finalmente, ¿cómo influye la participación de estos jóvenes en el Proyecto en las significaciones y prácticas políticas que vivencian en sus territorios? El texto cita de manera generosa la voz de los participantes de la investigación con el fin de compartir las narrativas que sustentan los análisis.

\section{CiUdadanía y CULtURA POLítica}

Tal como ha sido resaltado por varios estudios, el ejercicio ciudadano de los jóvenes no se suscribe necesaria ni principalmente a los mecanismos provistos institucionalmente por los Estados (Reguillo, 2003; Martínez, 2008; Henao y Pinilla, 2009; Cubides, 2015), lo que lleva a cuestionar las perspectivas con las que puede ser leído y las nociones de democracia que le sustentan. En este sentido, el concepto hegemónico de ciudadanía adscrito a las tradiciones liberales, el cual se sostiene en el estatus jurídico que otorga al individuo derechos civiles, sociales y políticos al ser parte de una comunidad política, ha sido cuestionado en tanto ha reducido la participación en lo público a un asunto individual expresado en el voto, lo que ha conducido a la constitución de una ciudadanía pasiva y a la erosión de la cohesión social (Kymlicka y Wayne,1994; Mouffe, 1999; Henao y Pinilla, 2009). Adicionalmente, ha sido revisado críticamente la abstracción del sujeto libre y ahistórico en la que se sustenta esta tradición, pues ha servido para excluir sujetos subalterizados por razones de género, edad, etnia, racialización, entre otros; del supuesto goce indiscriminado de derechos (Pateman, 1996).

De otro lado, la tradición republicana condice la ciudadanía a la participación política como forma de coexistencia social y, por tanto, el centro de las vidas de las personas. Por su parte, el comunitarismo señala la necesidad de comprender a un sujeto situado, dotado de identidad(es) y miembro de 
comunidades — que no se agotan en la nación—, lo que genera posicionamientos y pertenencias que configuran las prácticas ciudadanas (Kymlicka y Wayne, 1994). Asimismo, contribuyen a la discusión la noción de ciudadanía insurgente propuesta por Holston (2009), quien identifica en los pobladores periféricos de las ciudades - de Brasil, en su investigación - el ejercicio de una ciudadanía que se escapa a los ejes de la política de las democracias liberales, y que se caracteriza por una membresía definida por la residencia urbana y la reivindicación de derechos concretizados en el derecho a la ciudad. En resonancia con estos enfoques, desde una perspectiva que entiende que la ciudadanía ejercida por las juventudes locales excede los cánones de los enfoques liberales y, en este sentido, no se agota en el estatus jurídico determinado por la pertenencia a una comunidad política y un sujeto abstractos, se realizó un desplazamiento hacia su dimensión práctica e histórica.

Ahora, si bien la idea de lo referido por el término de cultura política puede rastrearse desde el pensamiento clásico, como categoría se vincula a los desarrollos teóricos adelantados por Almond y Verba en el campo de las ciencias políticas en los años 60 (Heras, 2002; Rodríguez, 2017). A partir de la caracterización de la cultura cívica concebida como el tipo ideal de cultura política, estos autores integraron la variable cultural en su trabajo por responder al cuestionamiento de por qué solo algunas sociedades democráticas alcanzan determinados estándares. En su enfoque behaviorista, la cultura política hace referencia a las orientaciones de orden psicológico - cognitivas, emotivas y evaluativas - que tienen los individuos respecto a los objetos políticos (procesos de decisión, roles, decisiones, entre otros) que constituyen el sistema político (Almond y Verba, 1963). Orientaciones que determinan la manera que se produce la acción política.

La adscripción a un modelo ideal de cultura política representado por países como Inglaterra o Estados Unidos sustentó que el enfoque behaviorista fuera tachado de etnocéntrico, lo que implicaba una lectura sesgada a otras 
construcciones políticas que no necesariamente se ajustan a ese modelo ideal (Heras, 2002; Rodríguez, 2017), y especialmente la manera en que estas construcciones políticas se desenvuelven dentro de contextos particulares. En consecuencia, desde la corriente interpretativa desarrollada en el marco de las ciencias sociales en los años 80 es planteada una perspectiva de la cultura política que reconoce su carácter histórico, y en la que tienen lugar la observación de aspectos subjetivos e intersubjetivos, además de una comprensión de la política que va más allá del sistema político institucionalizado.

La corriente interpretativa embebe del interaccionismo simbólico, la fenomenología y la teoría interpretativa de la cultura de Geertz (Heras, 2002; Rodríguez, 2017). En este marco, es comprendida como sistemas de significado de lo político, los cuales son elaborados en procesos de socialización política a partir de las experiencias individuales y colectivas vinculadas a la vida cotidiana. En esta línea, apunta Lechner (1997), la política institucionalizada, aunque centro de poder, no logra contenerlo y este se diluye en el mundo social en escenarios de micropoder e informalidad. Así, la cultura política no define una categoría abstracta, sino relacional referida a los sentidos construidos y negociados de manera intersubjetiva en contextos históricos y geográficos en torno a lo político. De allí que sea necesario estudiar la acción política inserta en las prácticas sociales y los escenarios locales de la política; las representaciones sociales de la vida política — valores, creencias, discursos, etc.—y cómo son construidas intersubjetivamente a lo largo de la vida de las personas; y las maneras en que se desenvuelven y significan las relaciones de poder (Lechner, 1997), entre otros, con el fin de descodificar los sentidos de lo político construidos por determinados actores o sociedades. 


\section{Metodología}

El estudio se apoyó en la sistematización de experiencias. Este método de investigación de carácter cualitativo concibe las experiencias como procesos históricos y sociales dinámicos y complejos. De acuerdo con Jara (2000), permite explicitar las lógicas y la comprensión teórica de una o varias experiencias a partir de la reconstrucción de los factores que intervinieron, su ordenamiento e interpretación crítica. Por su parte, señala Ghiso (2013) que esta estrategia metodológica permite la construcción de conocimiento sobre las prácticas desarrolladas mediante ejercicios dialógicos y reflexivos, los cuales se realizan sobre narrativas y registros escriturales que permiten recuperar, tematizar y apropiar las acciones realizadas con el fin de relacionar analíticamente sus componentes prácticos, teóricos, técnicos, éticos y políticos $\mathrm{y}$, con ello, comprender los sentidos y aspectos problemáticos de la experiencia.

El eje de la sistematización lo constituyeron las prácticas pedagógicas apropiadas por los jóvenes dinamizadores que participan del Proyecto y su incidencia en la transformación de la cultura política, del cual se desprendió analíticamente un subeje de indagación: la comprensión y la transformación de la cultura política desde los dinamizadores como sujetos situados, sobre el cual se basa el presente artículo. En esta línea, el diseño metodológico estableció un primer momento de recuperación y reconstrucción de la práctica de la participación de las y los jóvenes dinamizadores en el proyecto por un período de tres años $(2013,2014,2015)$. Entre los procedimientos contemplados estuvieron la identificación de referentes generales de la experiencia: institucionales, situacionales y teóricos; la realización de inventario documental con la información ya generada por la experiencia - documentos orientativos, informes de los equipos técnicos que acompañan el Proyecto y material de registro, entre otros- y la generación de información con los actores de la experiencia. La producción de información con las y los jóvenes participantes contempló la realización de tres grupos focales, la observación participante de 
cuarenta y dos sesiones formativas (de profesionales sociales con dinamizadores y de dinamizadores con niños y niñas), veinte entrevistas semiestructuradas a jóvenes dinamizadores y el diligenciamiento de catorce instrumentos individuales que convocaban a la reflexión y el relato de las experiencias de esta población juvenil.

Dado que los Semilleros Infantiles para la participación usualmente ${ }^{8}$ tienen presencia en todas las comunas y corregimientos de la ciudad —en varios de sus barrios-, las y los jóvenes que participan en calidad de dinamizadores tienen a su vez orígenes y características diversos, lo que, en parte, es determinado por los criterios de operación del Proyecto, pues se precisa que sean jóvenes entre los 16 y 25 años provenientes de los barrios en los que se desarrollan los semilleros. La caracterización realizada en el período de estudio arrojó, entre otros, que el segmento de edad de mayor proporción está entre los 21 y 23 años; de acuerdo con la estratificación socioeconómica municipal, un promedio de $27 \%$ pertenece a un nivel socioeconómico bajo-bajo, $54 \%$ a uno bajo, un $21 \%$ entre niveles medio-bajo y medio y un $1 \%$ a un nivel medio-alto; en promedio, el $75 \%$ son mujeres; y alrededor de un $50 \%$ a $60 \%$ ha cursado o se encuentra cursando educación técnica, tecnológica o universitaria. En este marco, del grupo de los — alrededor - de doscientas dinamizadoras y dinamizadores que participan cada año, la aplicación de las técnicas se hizo a partir de un muestreo cualitativo de tipo teórico, en el que la selección de los participantes tuvo como base el cubrimiento de una variabilidad de individuos que representan tipos significativos para el tópico de investigación (Mallimaci, 2004), en este caso se tuvieron en cuenta criterios de género, edad, comuna de pertenencia y antigüedad

\footnotetext{
${ }^{8}$ La continuidad del número de semilleros responde a la disponibilidad presupuestal anual destinada por el Municipio de Medellín al Proyecto. Este margen presupuestal está constituido en un alto porcentaje por recursos del Presupuesto Participativo (PP), un programa que permite que el 5\% de los recursos anuales de inversión del Municipio de Medellín sean definidos participativamente mediante procesos asamblearios y de votación organizados por comunas y corregimientos.
} 
de participación en el Proyecto.

Un segundo momento de tematización y análisis de la información tuvo como objeto develar y construir de manera reflexiva los sentidos de la experiencia. En coherencia con la sistematización como método, la construcción de las categorías de indagación y análisis obedecieron a un proceso constante, que partió del enfoque teórico pero que estuvo atento al refinamiento y la emergencia de categorías emergentes. Así, de acuerdo con el eje de la pesquisa, el enfoque teórico y la producción de la información, la propia investigación permitió señalar la plausibilidad de las categorías de indagación y análisis definidas: poder (significaciones, despliegue e implicaciones en los escenarios locales), socialización política (representaciones y valoraciones de la participación en la vida cotidiana y de los escenarios locales de participación), ciudadanía (reconocimiento, defensa y ejercicio de derechos y deberes e identificación con una comunidad política) y acción política (prácticas y repertorios participativos en los escenarios locales). Como puede leerse en el presente texto, estas categorías sirvieron a la profundización y organización del análisis, sin ello desconocer sus conexiones y mutuas afectaciones.

Finalmente, fue implementado un tercer momento de socialización y discusión de resultados.

\section{CONTEXTO DE PODERES: LOS ESCENARIOS LOCALES DE LA POLÍTICA DESDE LA LECTURA DE LAS Y LOS JÓVENES DINAMIZADORES}

La comprensión que realizan las y los jóvenes de los elementos constitutivos del entorno político deviene en gran medida de representaciones que expresan a través de narrativas asociadas a su ser y estar en los territorios; a sus experiencias y lecturas del mundo, dentro de las cuales sobresalen las 
discusiones en torno al poder, pues la manera en que este se desenvuelve en sus contextos configura las relaciones con lo público, constriñe o posibilita la acción política, contextualiza y determina el ejercicio ciudadano y, por ende, condiciona los escenarios colectivos que identifican los jóvenes (Ocampo, 2011; Botero, Torres y Alvarado, 2008). En este sentido, el análisis de los escenarios locales de la política, desde la lectura de las y los jóvenes, parte por preguntarse: ¿quiénes ostentan el poder en los territorios? ¿Cuáles relaciones favorecen que algunos actores ostenten el poder? ¿En qué escenarios se despliegan y son identificados?

De acuerdo con el foco de la investigación, los escenarios sociales y comunitarios de participación, por un lado, y los que conforman los actores ilegales, por el otro, configuran campos de tensión en cuanto a las relaciones de poder que se tejen dentro de los contextos de las y los jóvenes. El primero, pautado por la influencia que ejercen quienes tienen más representatividad y trayectoria (sobre todo en espacios como las Juntas de Acción Comunal); el segundo, por las limitaciones a las libertades de expresión, las amenazas y el ejercicio de la violencia. Adicionalmente, un tercer actor emerge en las narraciones de los jóvenes pero de manera menos representativa: el Estado y el gobierno asociado más directamente al poder de decisión frente a los recursos públicos.

Vale apuntar que, en los discursos de las y los jóvenes dinamizadores, se identifican lecturas poco favorables del poder ejercido por los y las líderes tradicionales de los territorios, pues, desde su acervo político, este no propicia la construcción de relaciones plurales y el encuentro de colectividades, sino que constriñe, limita y hasta anula las posibilidades de participación en los barrios y comunas. De acuerdo con Reguillo (2003), se develan rasgos que aluden a una ciudadanía restringida, determinada por estructuras formales en las que se establecen divisiones arbitrarias entre «menores»y «mayores de edad», en las que los primeros carecen de los suficientes derechos y capacidades para participar de la esfera pública. 
La tensión entre los liderazgos juveniles y tradicionales obedece en buena parte al desencuentro que vivencian los primeros cuando quieren integrarse a los escenarios de participación establecidos. De esta forma, sobresalen comentarios que indican cómo se manipulan los espacios de participación para que no tengan cabida nuevos actores e ideas:

Porque ellos ya tenían toda la «dinámica» completa. Entonces hay unos líderes que manejan todo el grupo y es lo que ellos digan... O los líderes ya tienen planeado qué van a hacer... Entonces no están dispuestos a nuevas ideas. Entonces al uno ver que uno no tiene cabida contra esa mayoría, se va. O se incluye en esa dinámica que no es correcta ${ }^{9}$.

Hay muchos jóvenes... pero siempre tenemos «la pared» ahí que nos impide... porque los que tienen el poder quieren sobresalir ${ }^{10}$.

Este tipo de acotaciones advierten una desestimación del ejercicio de la ciudadanía de los jóvenes en los territorios, que se alimenta del statu quo reproducido por los marcos de actuación de los liderazgos tradicionales: «Nunca uno se da cuenta de lo que pasa en nuestra comuna. Cuando eligen a un presidente [de la JAC] no cuentan, entonces siempre va a tener la misma persona el mismo poder» ${ }^{11}$. Tal como se evidencia en otros escenarios «formales» de participación (Cubides, 2015; Martínez, 2008), los jóvenes tienden a ser marginados, especialmente cuando no se adecúan a los patrones legitimados por los más adultos. Con todo esto, en las expresiones juveniles emerge un sentido crítico frente a cómo se despliega el poder por parte de los líderes tradicionales, quienes erigen y consolidan micropoderes hegemónicos impuestos mediante el control de quién participa y cómo lo hace. De esta manera, los escenarios de participación más convencionales en los territorios enmarcan luchas de poderes entre quienes

\footnotetext{
${ }^{9}$ Entrevista a joven de la ciudad de Medellín, Antioquia, septiembre 6 de 2015.

${ }^{10}$ Entrevista a joven de la ciudad de Medellín, Antioquia, septiembre 16 de 2015.

${ }^{11}$ Entrevista a joven de la ciudad de Medellín, Antioquia, octubre 5 de 2015.
} 
lo ejercen y quienes pretenden revertir su fuerza.

En este aspecto, y en coherencia con lo planteado por Bourdieu ([1993] 2002), los escenarios de participación se convierten en campos de poder en los que se negocia el orden vigente. En este caso, quienes dominan el campo y, por tanto, toman las decisiones. Y es en este marco de tensión por la disputa del poder que los jóvenes sienten la fuerza del ser desconocidos y, por tanto, excluidos. Lo cual se alimenta e incide en la reproducción de una imagen estereotipada de los liderazgos ejercidos por los adultos como interesados y monopolizadores de los recursos públicos de los territorios locales.

Sin embargo, a pesar de ser referida esta tensión como un aspecto sobresaliente y determinante, también lo es que, en la negociación por la reproducción del orden vigente, se han dado intersticios que cruzan los abismos intergeneracionales en la participación. De esta forma, algunos jóvenes refieren transformaciones en cómo se están relacionando con los liderazgos adultos:

Y hay algo muy importante: que acá se logró trascender esas barreras intergeneracionales entre los jóvenes y adultos, esa bobada de iqué pereza ir y participar en un espacio con los adultos!, teniendo la idea errada de que ellos tenían el monopolio de todo. Pero ahorita los jóvenes y los adultos se han venido comunicando y relacionando de otras maneras. De hecho, se han hecho muchos proyectos intergeneracionales donde se pueden sentar en un mismo espacio y dialogar de una manera muy bonita ${ }^{12}$.

Ahora bien, como se mencionó, existe otra clase de actores en la ciudad que, con su poder ilegal, determinan el curso de muchas dinámicas participativas en los territorios. Estos son mencionados como «los combos», «los muchachos», «los grupos armados», «los grupos criminales» o «los vándalos», pero, en general, se refiere a un actor que intimida y se impone por medio de la violencia y el crimen organizado y, con ello, influye de manera determinante en los

\footnotetext{
${ }^{12}$ Entrevista a joven de la ciudad de Medellín, Antioquia, septiembre 16 de 2015.
} 
espacios de participación de los territorios de la ciudad, pues son «los grupos armados los que toman la mayoría de decisiones en la mayoría de conflictos. La comunidad de hecho acude más fácil a ellos que a la misma policía» ${ }^{13} \mathrm{y}$ «en espacios públicos uno se siente amenazado [...], entonces uno no puede decir abiertamente lo que piensa» ${ }^{14}$.

Las bandas criminales ejercen influencia en el desarrollo de la participación juvenil no solo a partir de las dinámicas propiamente delictivas, ya que reproducen y fortalecen su poder precisamente al integrarse a las prácticas sociales y comunitarias cotidianas de los territorios. Es así como interfieren y se traslapan con el ejercicio de los poderes ejercidos por los liderazgos sociales y comunitarios:

¿Y no hay conflicto entre la JAC y esos combos? No. Antes trabajan muy de la mano. A veces los mariguaneros le dicen a la JAC que vamos a hacer un torneo relámpago (de algún deporte) y de la JAC les consiguen medallas, refrigerios [...]. Las bandas criminales coaccionan la participación. De cierta manera, los líderes también han legitimado ese actuar, entonces esas personas están inmersas en todos los proyectos y uno no puede participar libremente de todas las $\operatorname{cosas}^{15}$.

Tácitamente se teje una sintonía entre las acciones de unos y otros que puede ser controversial, pero que, en cualquier caso, evidencia en los territorios una marcada influencia de los actores ilegales muy cercano a la intimidación, pues las y los jóvenes hablan de ellos con impotencia y temor. Son actores que no se interpelan porque «es poner la propia vida en peligro».

\footnotetext{
${ }^{13}$ Entrevista a joven de la ciudad de Medellín, Antioquia, septiembre 27 de 2015.

${ }^{14}$ Entrevista a joven de la ciudad de Medellín, Antioquia, octubre 30 de 2015.

${ }^{15}$ Entrevista a joven de la ciudad de Medellín, Antioquia, octubre 11 de 2015.
} 


\section{PERCEPCIONES Y ANÁLISIS DE LOS ESCENARIOS LOCALES DE PARTICIPACIÓN}

En el horizonte de comprender los sentidos de la participación construidos por los y las jóvenes en el contexto de su cultura política, abordar su concepción adquiere un lugar protagónico, pues sustenta tanto su marco de relacionamiento con lo público, como las acciones políticas que despliegan en sus cotidianidades. Así, los matices que adquiere la participación desde la interpretación de las y los dinamizadores resultan de experiencias y lecturas personales en los que tienen lugar; por un lado, apreciaciones focalizadas en aspectos más políticos de la participación, en tanto resaltan su atributo decisorio; por el otro, aquellas que la identifican con la posibilidad de reunión:

Para mí, la participación es la oportunidad de incidir en ciertos espacios como personas, de dar nuestra opinión, de poder participar desde nuestro ser, desde nuestro hacer y que no necesariamente son escenarios políticos o institucionales ${ }^{16}$.

Puede afirmarse que al señalar la posibilidad de acordar, incidir y decidir se atiende a la dimensión política de la participación. No obstante, para este grupo de jóvenes la connotación política entraña una tensión. Algunos de ellos y ellas expresan rechazo respecto a lo político como si se tratara de una esfera externa y pesada: «Me dicen algo de político, yo digo no, ¡qué pereza! El interés de uno no es hacia eso, entonces es como falta de incentivar de que los proyectos sean como más del interés de nosotros»» ${ }^{17}$.

Esta suerte de despolitización o distanciamiento de la política del concepto de participación, se soporta en una representación negativa del ejercicio público convencional en el ámbito local e incluso nacional. Una desconfianza hacia las instituciones que se hace reconocible en la construcción de las

\footnotetext{
${ }^{16}$ Entrevista a joven de la ciudad de Medellín, Antioquia, noviembre 13 de 2015.

${ }^{17}$ Entrevista a joven de la ciudad de Medellín, Antioquia, noviembre 6 de 2015.
} 
ciudadanías juveniles (Varón, 2014). Así, se rechaza aquello que se identifica con la política tradicional, y su espectro se amplía hacia la posibilidad y la riqueza de encontrarse con el otro, el acercamiento a escenarios de reunión e interacción o la adherencia a grupos y equipos.

También pueden ser muchos otros espacios, yo considero la participación desde el punto donde hay cuatro o cinco pelaos (jóvenes) reunidos, tocando guitarra, departiendo, hablando sobre asuntos que nos interesan a todos. Y es tener la oportunidad de tomarse la palabra ${ }^{18}$.

Pese a que este tipo de significaciones sobre la participación buscan apartarse de lo político, la mayoría de las concepciones terminan moviéndose hacia su génesis; opinar, discernir o al menos propiciar espacios para ello; pero siempre brindando mayor relevancia a los ejercicios cercanos a la cotidianidad y a la reunión, lo que le otorga a la participación un carácter habitual, colectivo y socializador. Se encuentra entonces que los procesos de participación se ofrecen y a la vez son resultado de la construcción intersubjetiva en los que la interacción con el otro y los otros da paso a la construcción de un sentido del nosotros y unos objetivos comunes (Henao y Pinilla, 2009; Bermúdez, Parra, Patarroyo y Peña, 2013).

Ahora bien, el concepto que expresan de la participación obedece a las lecturas que realizan respecto a las condiciones, circunstancias y formas en que se emprenden acciones políticas en sus territorios. Las reflexividades que transmiten sus voces como dinamizadores/as de un proceso formativo de participación ciudadana permiten acercarse a una suerte de diagnóstico del estado de la participación en sus territorios, en el que pueden distinguirse tres ejes de discusión, además de los conflictos intergeneracionales ya mencionados, a saber: apatía política, deficiencias en la articulación de procesos y representatividad de

${ }^{18}$ Entrevista a joven de la ciudad de Medellín, Antioquia, octubre 18 de 2015. 
los escenarios tradicionales.

En esta línea, para las y los dinamizadores, en la mayoría de los espacios de socialización en los que participan —especialmente familia y escuela - se expresa y reproduce una apatía por lo político. De esta forma, el desconocimiento del ejercicio político local o la evasión frente al tema de lo político se convierten en factores clave de los procesos de socialización política de las y los jóvenes, pues instalan valoraciones que orientan sus concepciones y accionar político:

Desde mi experiencia en el colegio, no nos preparaban para tener una conciencia política, por el contrario, desde este espacio, se generaba y se afianzaba la apatía puesto que los mismos docentes hablaban de la corrupción, de que los políticos eran unos ladrones, pero nunca nos enseñaron los escenarios donde podemos participar y la importancia de estos procesos ${ }^{19}$.

La manera en que se inserta el tema de la apatía política en el proceso de socialización política, entendido como la relación entre las experiencias que configuran la identidad social y la interacción con el sistema político y sus instituciones (Alvarado, Ospina y García, 2012), explica en buena medida esa despolitización — formal— del concepto de participación de la que se habló antes. Y, si bien las y los jóvenes denuncian de manera crítica el no ser formados para comprender y dinamizar los espacios políticos, siguen reproduciendo esta misma apatía con sus discursos acerca del ejercicio político convencional.

A pesar de la desafección política que identifican genéricamente en su sociedad las y los jóvenes, existe en la ciudad una diversidad de escenarios de participación. Pero desde su mirada diagnóstica, una de las principales falencias del ejercicio participativo en los territorios es que el funcionamiento de estos escenarios sufre de desarticulación entre procesos y actores. El asunto neurálgico es que la segregación de los procesos impide que se produzcan los resultados e impactos esperados, pues las y los jóvenes atestiguan cómo nacen y languidecen

\footnotetext{
${ }^{19}$ Entrevista a joven de la ciudad de Medellín, Antioquia, septiembre 30 de 2015.
} 
proyectos en los territorios, sobre todo cuando obedecen a acciones puntuales propias del activismo tanto institucional como comunitario. Desde el acervo político de las juventudes, esta no es otra cosa que restar incidencia a los ejercicios de participación, pues «el que hace la escuela de fútbol es "aparte”, el que hace el grupo de baile es aparte, entonces no se unen para nada. Ahí es donde falla la participación y no se genera un impacto grande para la comunidad. Entonces se ven como entes, así, aislados. Entonces la gente no les da la importancia que se merecen ${ }^{20}$.

Por otro lado, aunque la mayoría de las y los jóvenes refiere a formas alternativas de participación acordes con las diversas expresiones del ser joven, los escenarios promovidos o acompañados por las instituciones gozan de alto reconocimiento en la significación y valoración de la participación. La constante referencia a los espacios tradicionales de participación comunitaria (como Juntas de Acción Comunal), de representatividad comunal (como Juntas Administradoras Locales) y de presupuestación participativa, refleja no solo su vigencia dentro de los territorios, sino que devela su vinculación al sentido que se construye de la participación. A pesar de suscitar fuertes críticas, la representatividad de estos escenarios tradicionales de participación parecen constituir centros gravitacionales de los sentidos construidos por los jóvenes sobre la política local, especialmente el programa denominado Planeación Local y Presupuesto Participativo (PL y PP) ${ }^{21}$ que es referido como un componente inherente al ejercicio de participación en los territorios, quizás porque en él convergen (o al menos se convoca) prácticamente todos los actores que hacen parte del tejido organizativo de los territorios, convirtiéndose así en plataforma de interacción y en espacio de dinamización.

\footnotetext{
${ }^{20}$ Entrevista a joven de la ciudad de Medellín, Antioquia, septiembre 23 de 2015.

${ }^{21}$ Ver nota al pie $\mathrm{N}^{\mathrm{o}} 6$.
} 


\section{DINÁMICAS Y TENSIONES DE LA PARTICIPACIÓN JUVENIL}

\section{EN LOS ESCENARIOS LOCALES DE LA POLÍTICA}

Ha sido la concepción de las juventudes frente a la participación la que se ha venido tratando hasta este punto con el fin de abordar esa dimensión de la cultura política asociada a las significaciones de los escenarios políticos locales, entendidos como escenarios de socialización política: cómo se comportan desde el lente de las y los jóvenes. Sin embargo, es preciso ahondar en la lectura que ellos y ellas realizan de sí mismos en su condición de jóvenes y la manera cómo se vinculan precisamente a estas significaciones, pues referencian la manera en que se viven, reproducen, interpelan y redefinen en sus prácticas ciudadanas y de participación; entre otros, los espacios de participación que impulsan, las particularidades que aducen de sus formas de participar y las valoraciones y los horizontes de sentido que les sustentan.

Conforme con lo expuesto, la apatía como respuesta generalizada a los espacios formales de participación también se extiende a las mismas juventudes, quienes encuentran pocas motivaciones para vincularse a ellos. Sin embargo, lo que para algunos representa una nula participación juvenil, para otros es la expresión de formas de incidencia política que actúan de manera alternativa respecto de los canales formales. Como se apuntó antes, no es que las juventudes no consideren la importancia de la participación, sino que le otorgan significaciones distintas, la recrean desde sus propias visiones y opciones contextuales, trascendiéndola más allá de lo convencional o de la vinculación a la institucionalidad: «Hay que diferenciar las formas de participar. Por el hecho de que el joven no vaya a un grupo, no significa que no está participando. Está participando de otra manera y está poniendo otras cosas que para él son de más interés» ${ }^{22}$.

${ }^{22}$ Entrevista a joven de la ciudad de Medellín, Antioquia, octubre 10 de 2015. 
Este tipo de afirmaciones, esencialmente reivindicativas, demuestran que aunque los escenarios tradicionales siguen dominando el campo de representaciones que configura los escenarios políticos locales, en sus fisuras emergen otras formas de ser y ejercer la participación y lo político más acordes con las diferentes expresiones del ser joven. Nos habla entonces de una ciudanía juvenil que interpela miradas adultocéntricas de la participación y el ejercicio de la ciudadanía, las cuales redefinen los sentidos de lo público y las prácticas ciudadanas (Arias-Cardona y Alvarado, 2015), para así ampliar con ello la propia concepción de lo político y vincularla con los afectos y las experiencias cotidianas que viven las y los jóvenes en sus territorios (Patiño, Alvarado y Ospina, 2014). Particularidad que obliga alejarse de interpretaciones rápidas que les tildan de apáticos y desinteresados frente a las problemáticas colectivas y, en cambio, reconocer cómo reconfiguran lo político desde sus subjetividades (AriasCardona y Alvarado, 2015).

Emerge así un amplio abanico de repertorios de participación en los que se incluyen los convencionales y los no convencionales. En este sentido, se expresan como escenarios de participación tanto los que ostentan reconocimiento institucional (mesas de jóvenes de la comuna o corregimiento, comisiones de juventud, asambleas barriales), como aquellos espacios de encuentro e interacción que usualmente escapan a las categorizaciones de participación ciudadana. En esta línea, desde las narrativas de las y los jóvenes dinamizadores, la música y la danza adquieren un lugar protagónico, especialmente el hip-hop, que es rescatado como dispositivo y ventana de expresión juvenil desde la denuncia y el reconocimiento de contextos históricamente desiguales y de exclusión. Pero más allá de las particularidades y énfasis puestos en cada repertorio, lo importante para las juventudes es que «estamos transformando esa idea de que los jóvenes no participamos» ${ }^{23}$, porque «son ya los jóvenes líderes

${ }^{23}$ Entrevista a joven de la ciudad de Medellín, Antioquia, septiembre 23 de 2015. 
los que quieren aportar a su barrio, quieren aportar a proyectos y quieren sacar proyectos para ellos» ${ }^{24}$. Afirmaciones comunes que coinciden con los hallazgos de otras investigaciones en las que las y los jóvenes se autorreferencian como sujetos transformadores de sus realidades (Agudelo et al., 2013).

En las narrativas de las y los jóvenes, se revela una autopercepción como seres llenos de pasión y convicción en el despliegue de su ejercicio político. No obstante, la efervescencia subyacente a ellas simultáneamente es asociada con la inconcreción y la inconstancia, lo que dificulta pasar de la reflexión a la acción. Así, paradójicamente, su crítica o valoración sobre la incidencia y constancia de los jóvenes en los escenarios locales de participación se vincula con una suerte de desbordamiento de la pasión juvenil.

\section{ACCIÓN POLÍTICA Y TRANSFORMACIONES DE LA CULTURA POLÍTICA LOCAL DESDE LA SUBJETIVIDAD DE DINAMIZADORES/AS DE PROCESOS FORMATIVOS PARA LA PARTICIPACIÓN}

El emprendimiento de acciones directas en los escenarios de participación depende de la manera en que se asume aquello de «ser ciudadano/a»; trascender el concepto más allá del plano jurídico para trasladarlo a la cotidianidad del encuentro y la relación con los otros, permite asumir la posibilidad y responsabilidad de construir realidades colectivamente. Es en la acción política que los jóvenes interpelan y amplían el sentido de lo político a partir de sus creaciones, afectaciones y movilizaciones (Patiño, Ospina y Alvarado, 2014).

En general, el grupo de jóvenes sujeto de la investigación señala ejercer una participación constante y activa. En su mayoría, los dinamizadores y las

${ }^{24}$ Entrevista a joven de la ciudad de Medellín, Antioquia, octubre 16 de 2015. 
dinamizadoras de procesos formativos del Proyecto afirman estar vinculados(as) a alguna organización o iniciativa comunitaria. La necesidad sentida de ser agentes de cambio y la cercanía previa a procesos de participación se destacan como importantes motivaciones del pleno ejercicio político, lo que también impulsa a emprender iniciativas de las que las y los jóvenes son cofundadores, tal como se expresa en la cita:

La participación llega a mi vida en el 2013, un año en el cual empezaba a ser parte del equipo de trabajo de la JAC Manila. En el 2014, junto con otros seis amigos/as jóvenes que nos encontramos en P.P creamos la Mesa de Jóvenes de la Comuna 14, una organización social sin ánimo de lucro que se preocupa por la participación de los jóvenes en la comuna y la inclusión de los mismos en los diferentes espacios públicos y privados; es así como todos los temas tratados con los niños los puedo practicar en la organización de la cual hago parte ${ }^{25}$.

Participar en ciertos espacios motiva su articulación con otros. Así, se da una conexión estimulante entre la participación en un proceso y el establecimiento de vínculos con otros escenarios. De esta manera, se diversifican los repertorios de participación para las juventudes, fenómeno que ellas suelen asociar a la pasión característica de su ejercicio político, ya mencionada, y al dinamismo que en la mayoría de las ocasiones impulsan nuevas interacciones, adherencias e inquietudes:

Aparte de la Junta, soy la gestora editorial del periódico La Pupila, estoy como dinamizadora en esto, algunas veces realizo acompañamientos parcialmente a lo que viene sucediendo en Presupuesto Participativo, también estoy en la Escuela de Comunicaciones de la comuna, y también tengo una afiliación política, lo que me genera contacto con un partido político en el cual yo he tenido la posibilidad de conocer personas... y también a comprometerlas con mi territorio ${ }^{26}$.

\footnotetext{
${ }^{25}$ Entrevista a joven de la ciudad de Medellín, Antioquia, noviembre 3 de 2015.

${ }^{26}$ Entrevista a joven de la ciudad de Medellín, Antioquia, octubre 16 de 2015.
} 
Ahora bien, no necesariamente las múltiples experiencias participativas a las que se vinculan las y los jóvenes dinamizadores generan satisfacción; al contrario, también se hacen manifiestos tránsitos participativos que desestimulan el ejercicio político. De esta forma, se nombran experiencias que agotan la convicción y pasión juvenil que afirman poseer, lo que deriva en un repliegue de su acción en los territorios: «Literalmente eso es una mierda (sic). Yo trabajo en la Comuna 2 con un proyecto de articulación juvenil... no podemos obtener recursos del PP sino de la Secretaría de Juventud... Eso es una locura... ¡Me salí del tema! ${ }^{27}$.

En cualquier caso, las y los jóvenes vinculados al Proyecto en calidad de dinamizadores y dinamizadoras enuncian redefiniciones en sus posicionamientos respecto a la participación y su ejercicio político como consecuencia del rol que asumen en este. Se identifica en las y los dinamizadores una transformación de las maneras en que significan las relaciones de poder desplegadas en sus entornos inmediatos y la comprensión de los escenarios de acción política desde la participación y el ejercicio de la ciudadanía; de entrada, esto denota aperturas cognitivas que potencian las capacidades transformadoras de las juventudes como sujetos políticos, pues el ejercicio del rol de formadores al interior del Proyecto, permite que se fisuren anteriores ideas para ampliar percepciones, sentidos y en general, marcos explicativos del mundo de lo político que determinan sus motivaciones y formas de participación en sus territorios.

Los dinamizadores y las dinamizadoras afirman que el trabajo que desarrollan les permite adquirir aprendizajes significativos en línea con lo definido por Ausubel, Novak y Hanesian (1983), en tanto no solo enseñan sino que aprenden, y desde allí transforman muchas de sus concepciones, lo que también tiene una dimensión práctica, ya que estas transformaciones motivan otras formas de ser y estar en el plano personal, familiar y social. De acuerdo con el relato de sus experiencias y reflexiones, el Proyecto posibilita la construcción

${ }^{27}$ Entrevista a joven de la ciudad de Medellín, Antioquia, septiembre 16 de 2015. 
de un aprendizaje que atraviesa su ser como sujetos, ciudadanos/as, profesionales, padres o madres de familia, lo que genera redefiniciones de sus comprensiones respecto de sus escenarios de vida $\mathrm{y}$, por ende, de las problemáticas que allí se presentan y las alternativas que eligen para hacerles frente.

Se sostiene que el reconocimiento o la profundización en el conocimiento de lo político se convierte en herramienta de poder que permite la construcción de sentidos más críticos, dado que «estar en este Proyecto y en este proceso nos permite tener conocimiento de herramientas que se pueden emplear... para participar, para ser tenidos en cuenta. Entonces, con respecto a eso, sí he aprendido bastante» ${ }^{28}$. De hecho, uno de los elementos que más se moviliza es el de la apatía política, ya que se da paso a otras formas de pensar que «desbloquean» el imaginario de que no hay posibilidades de transformación de lo público:

$\mathrm{Y}$ es que una cosa es la política y otra la politiquería. Entonces, nosotros tenemos una idea muy errada. Pero hasta que uno no conoce en sí la política, de pronto no llega a esa conclusión, sino que hace aportes o decisiones erróneas. Por ejemplo, para mí, política es tomar decisiones sobre asuntos públicos. Y eso hacemos en todos los espacios. Incluso aquí lo hacemos: hacemos política todo el tiempo; pero como la gente no entiende, entonces no lo aplica $^{29}$.

Cada una de estas aperturas cognitivas guarda una estrecha relación con nuevas visiones acerca de la ciudadanía, en la que los derechos y deberes dejan de ser un mero listado a enumerar, para convertirse en parte del sentido común. De esta manera, dinamizadores y dinamizadoras anudan su paso por el Proyecto a la adquisición de una mayor sensibilidad por las vulneraciones hechas a los

\footnotetext{
${ }^{28}$ Entrevista a joven de la ciudad de Medellín, Antioquia, octubre 10 de 2015.

${ }^{29}$ Entrevista a joven de la ciudad de Medellín, Antioquia, octubre 20 de 2015.
} 
derechos y de un mayor conocimiento sobre las iniciativas, programas e instituciones que aportan a su garantía y defensa:

Pero también creo que a nosotros nos ha fortalecido más, y digamos que no nos dejamos tanto, por los conocimientos que hemos adquirido, entonces en toda esta parte de control social, de las veedurías, de que sabemos a dónde recurrir, qué hacer para que no se nos vulneren los derechos; entonces eso es lo que ha hecho, digamos, con nosotros los procesos en los que hemos estado: ha potencializado nuestras capacidades, que permiten que no nos dejemos tan fácilmente ${ }^{30}$.

La inmersión en redes y escenarios políticos locales, ligado en cierta medida a las motivaciones y dinámicas del Proyecto, también permite que los dinamizadores y dinamizadoras transformen códigos de su cultura política. De esta manera, participar se convierte para las juventudes en un camino fértil, posible; se reafirma una credibilidad en los fines y logros de ser parte de escenarios de construcción colectiva.

Todo lo anterior repercute en las dinámicas concretas de los barrios y comunas de la ciudad en las que las y los jóvenes sienten contribuir a la transformación de las realidades de conflicto y violencia por medio del desplazamiento de poderes ilegales, ello al desinstalar aquellos dispositivos de socialización que potencian la inserción a bandas criminales. Las posibilidades promovidas desde el Proyecto de acceder a formas de vida diferentes compiten con otras que se imponen en sus contextos por los grupos criminales y «combos»:

Hay muchas comunas que por más difícil que sea la situación de seguridad... esos grupos de participación influyen en esos sectores... y muestran otra mirada a la situación que opaca en la comunidad. No desconocemos que en casi todas las comunas o en toda la ciudad hay grupos armados... que van haciendo una carga negativa a la ciudad... Pero entonces hay otros grupos que van dispersando en espacios y escenarios — canchas, ludotecas...-,

${ }^{30}$ Entrevista a joven de la ciudad de Medellín, Antioquia, octubre 16 de 2015. 
entonces, al ver un grupo que se moviliza hacia ese lugar de manera positiva, crítica y constructiva... hace que ese lugar cambie, tome otro foco... Entonces ya esos grupos (armados) van tomando otra salida... No con esto los grupos armados dejan de funcionar, pero estamos haciendo desplazar la violencia... Cuando a veces se presenta es lo contrario ${ }^{31}$.

Sumado a ello, las juventudes se enfrentan con los comportamientos que interpretan como excluyentes, creyendo posible transformar las relaciones de poder que condicionan su participación dentro de los escenarios políticos locales, sobre todo aquellas que tienen que ver con el ejercicio de liderazgos tradicionales: «Entonces claro, se pueden cambiar. Ya el señor de la Junta de Acción Comunal no es como años anteriores que a muchos de los "pelaos" [jóvenes], cuando iban a pedir algo allá, él era “ah, déjame yo miro”. — “iParce!, vamos a sacar la carpa para hacer eso", sí se pueden cambiar esas relaciones de poder» ${ }^{32}$.

Ahora bien, pese a que la investigación no contó con una línea base que permitiera evaluar cómo aumenta o no la vinculación de las y los jóvenes a escenarios de participación y el número de acciones que ejercen en el ámbito de lo colectivo luego de su vinculación al Proyecto, es posible identificar transformaciones en el ejercicio político consecuentes con las aperturas antes mencionadas. En general, las y los jóvenes se identifican como agentes de cambio en sus territorios como resultado de los procesos participativos con los que se comprometen, sean estos formales o informales, y la labor que desarrollan como formadores de niños y niñas.

Si comprendemos que una de las dimensiones de asimilación de la cultura política es por medio de los mecanismos de autorreferencialidad, a través de los

\footnotetext{
${ }^{31}$ Entrevista a joven de la ciudad de Medellín, Antioquia, noviembre 20 de 2015.

${ }^{32}$ Entrevista a joven de la ciudad de Medellín, Antioquia, septiembre 8 de 2015.
} 
cuales los sujetos construyen sus procesos identitarios y de conciencia reflexiva (Gómez, 2002), es posible identificar cómo las discusiones planteadas a los niños y niñas llevan a los dinamizadores y dinamizadoras a discernimientos morales sobre sus roles y posturas en la construcción de lo público. Situación que permite aducir que el proyecto aporta a la configuración de una subjetividad política, al entender que «la subjetividad e identidad políticas constituyen al sujeto en constructor de realidades y de posibilidades colectivas para la vida en común» (Alvarado y Ospina, 2009: 56). Así, los conceptos y realidades que pretenden que los niños y niñas conozcan y problematicen, generan en ellos una reflexividad que motiva inserciones más activas en los escenarios de participación:

Cuando me inicié por allá en el 2012 sentí la necesidad de hacer parte de procesos de la comuna, porque implicaba que había que adquirir la información mínima de tu territorio para compartirla con los niños y niñas. Y creo que ahí fue donde empecé a vincularme más. Yo hacía parte muy superficial... muy someramente iba a encuentros y reuniones. Pero realmente con la convicción de que era necesario hacerlo... fue a partir de la entrada a semilleros ${ }^{33}$.

Yo estoy desde el 2013, donde la Alcaldía hizo la prueba piloto de poner por primera vez un semillero en El Poblado. Y también fue para mí una prueba piloto empezar a participar en proyectos sociales. Lo mío es trabajar en proyectos sociales... desde eso no he parado de trabajar. Porque, si yo estaba incentivando a los niños a que participaran, ¿yo por qué no lo voy a hacer? Entonces eso también me sirvió para ser el fundador de la Mesa de Jóvenes de mi comuna $^{34}$.

Ahora bien, junto con esta participación activa que dicen asumir motivados por su vinculación al Proyecto se encuentran las transformaciones que agencian en los niños y niñas, en un marco en el que las juventudes extienden los cambios en las significaciones y el ejercicio de la ciudadanía a los sujetos que acompañan. Esto da paso a resignificaciones del presente, sostenidas también en

\footnotetext{
${ }^{33}$ Entrevista a joven de la ciudad de Medellín, Antioquia, septiembre 16 de 2015.

${ }^{34}$ Entrevista a joven de la ciudad de Medellín, Antioquia, noviembre 3 de 2015.
} 
la consideración del futuro, la generación de expectativas y la confianza en la transformación de otros y otras. Los conceptos que aprehenden y las discusiones que movilizan los convierten en mediadores para que niños y niñas construyan su posición frente a la sociedad y sus entornos, y así en multiplicadores de esas significaciones que construyen y reelaboran:

Bueno, uno con eso hace un acercamiento. Por ejemplo, tengo una niña que cumplió 14 años y aún va al semillero como invitada... Y cuando fueron las asambleas barriales, ella fue y votó - porque ya tenía 14 años - ... Entonces, yo digo ¿de qué manera los semilleros están influyendo para que ellos, desde tan pequeños, estén en esas cosas de participación? Y ya muchos niños son «ay, cuándo cumpliré 14 para poder votar»... Y también se interesan más por lo que está haciendo la Junta, o por qué no los tienen o sí los tienen en cuenta $^{35}$.

Por otro lado, la representatividad adquirida en las comunidades por el hecho de ser dinamizadores y dinamizadoras genera en las y los jóvenes confianza a la hora de interlocutar y actuar en colectivo, propicia el reconocimiento como referentes en las comunidades, impulsa la vinculación a nuevos procesos y suscita el afianzamiento de sus liderazgos. Para este grupo de jóvenes, se abre un espacio para generar nuevos círculos de actuación y relaciones solidarias, pues las comunidades los identifican como actores de consulta y apoyo en asuntos políticos y estatales, dado el conocimiento que demuestran tener sobre ellos: «Somos como referentes de líderes sociales, a nosotros siempre están preguntándonos cualquier cosita, así sea de estudio o alguna cosa $\rangle^{36}$.

\footnotetext{
${ }^{35}$ Entrevista a joven de la ciudad de Medellín, Antioquia, noviembre 3 de 2015.

${ }^{36}$ Entrevista a joven de la ciudad de Medellín, Antioquia, octubre 16 de 2015.
} 


\section{Conclusiones}

Los resultados de la investigación evidencian que el Proyecto opera como un espacio de socialización política para las y los jóvenes, que junto con otros escenarios, posibilita una socialización lateral, asumida esta «como [parte de] un amplio abanico de opciones entre diversos modelos de socialización, que se amplía continuamente por las conexiones laterales entre iguales en la socialización política» (Gómez, 2002: 90). Así, el Proyecto se convierte en una opción significativa para las juventudes, pues genera fisuras en los sentidos cimentados en otros campos de socialización que tienen lugar en los territorios de la ciudad y que les plantean desesperanza, desconocimiento y vulneración de derechos. De tal forma que, desde el lenguaje de sus afectividades, estéticas e intereses abrazan la opción de reivindicarse, reconocerse e identificarse como sujetos constructores de cambio y agentes de transformación de realidades concretas.

En línea con otras investigaciones, fue posible determinar cómo los y las jóvenes reivindican que su ejercicio ciudadano sea comprendido desde la condición de juventud, y así aludir a una ciudadanía juvenil que cuestiona el sujeto abstracto y ahistórico sustentado en posturas liberales de la ciudadanía (Reguillo, 2003; Martínez, 2008; Varón, 2014; Cubides, 2015). De tal forma que, desde el lenguaje de sus afectividades, estéticas e intereses abrazan la opción de reconocerse e identificarse como sujetos constructores de cambio y agentes de transformación de realidades concretas. No obstante, este ejercicio ciudadano está tensionado por la cultura política que referencian y la manera que se despliega y reproduce en los escenarios locales. De allí que se resalte cómo los jóvenes que participan del Proyecto logren con sus prácticas interpelar los escenarios locales de la política a la vez que producen otros, lo que hace que esta ciudanía juvenil se comporte como prisma que interfiere en la configuración de la cultura política local: sus significados, relaciones de poder, interacciones con actores y escenarios, pues tal como lo señala Heras (2002), en las acciones 
políticas se negocia el orden vigente.

En este punto, es importante reconocer la manera en que el Proyecto, como escenario, provoca a su vez otros escenarios de socialización política en los que sobresalen los compartidos con los niños y las niñas - pero que no se agotan con ellos - al liderar y ser partícipes de diversas experiencias que se gestan y emergen en sus territorios, tales como mesas barriales, voluntariados y medios de comunicación alternativa en los que multiplican sus resignificaciones de la cultura política. En consecuencia, las movilizaciones que operan en los sentidos y las prácticas participativas no se anclan solo al mundo juvenil, pues este tipo de relacionamientos y vinculaciones hacen que se desborden y extiendan hacia otros sectores y poblaciones, dando paso también a nuevos campos de reflexividad sobre el mundo de lo político.

ENVIADO: 8 DE MARZO DE 2021

ACEPTADO: 8 DE ABRIL DE 2021 


\section{BIBLIOGRAFÍA}

Agudelo, A., Murillo, L., Restrepo, L. y PatiÑo, J. (2013). Participación ciudadana y prácticas políticas de jóvenes en la cotidianidad. Revista Latinoamericana de Ciencias Sociales, Niñez y Juventud, 11(2), 587-602.

Almond, G. y VerbA, S. (1963). La cultura cívica. Estudio sobre la participación política democrática en cinco naciones. Madrid: Euroamérica S.A. La Editorial Católica.

Alvarado, S. V., Ospina-Alvarado, M. C. y García, C. M. (2012). La subjetividad política y la socialización política, desde las márgenes de la psicología política. Revista Latinoamericana de Ciencias Sociales, Niñez y Juventud, 10(1), 235-256.

Alvarado, S. V. y Ospina, M. C. (2009). Contexto teórico para la reflexión sobre la socialización política. En G. TONON, Comunidad, participación y socialización política. Buenos Aires: Espacio Editorial.

Arias-Cardona, A. y Alvarado, S. (2015). Jóvenes y política: de la participación formal a la movilización informal. Revista Latinoamericana de Ciencias Sociales, Niñez y Juventud, 13(2), 581-594.

Ausubel, D., NovaK, J. y Hanesian, H. (1983). Psicología educativa: un punto de vista cognoscitivo. México, D.F.: Trillas. Traducción al español de Mario Sandoval P., de la segunda edición de Educational psychology: a cognitive view.

Bermúdez, D., Parra, D., Patarroyo, L. y PeÑa, M. (2013). Construcción de subjetividades en procesos de participación juvenil e incidencia en el desarrollo comunitario. Revista Aletheia, 5(1), 34-67.

BORDIEU, P. ([1993] 2002). Estrategias de reproducción y modos de dominación. Colección Pedagógica Universitaria (37-38), 1-21.

Botero, B., Torres, J. y Alvarado, S. (2008). Perspectivas teóricas para comprender la categoría participación ciudadana-política juvenil en Colombia. Revista Latinoamericana de Ciencias Sociales, Niñez y Juventud, 6(2), 565-611.

BRAND, E. (2018). Análisis de los aciertos y brechas en la promoción de la participación ciudadana en niños, niñas y jóvenes de la ciudad de Medellín. Caso Proyecto Semilleros Infantiles para la Participación. Revista de Ciencias Sociales Collectivus, 5(2), 130-152.

Cardona, M., García, H., Giraldo, C., López, M., SuÁrez, C., Corcho, D. et al. (2005). Homicidios en Medellín, Colombia, entre 1990 y 2002: actores, móviles y circunstancias. Cad. Saúde Pública. https://doi.org/10.1590/S0102-311X2005000300018. 
Cubides, J. (2015). Lo instituido y lo instituyente en los procesos de subjetivación política juvenil en Colombia, Chile y México. En F. E. Acosta, Jóvenes, juventudes, participación y políticas (pp. 135-184). Bogotá: Alcaldía Mayor de Bogotá.

GArcíA, B., Quiroz, A. y GonzÁlez, S. (2002). Técnicas Interactivas para la Investigación Social Cualitativa. Medellín: Fundación Universitaria Luis Amigó.

GHISO, A. (2013). Sistematización de prácticas educativas. Seminarios, Cali: Universidad del Valle.

Gómez, J. (2002). Aprendizaje ciudadano y formación ético-política. Bogotá: Universidad Distrital Francisco José de Caldas.

HenaO, J. y Pinilla, V. (2009). Jóvenes y ciudadanías en Colombia: entre la politización social y la participación institucional. Revista Latinoamericana de Ciencias Sociales, Niñez y Juventud, 7(2), 14051437.

Heras, L. (2002). Cultura política: el estado del arte contemporáneo. Convergencia. Revista de Ciencias Sociales, 9(30), 275-291.

JARA, O. (2000). Orientaciones teórico prácticas para la sistematización de experiencias. Centro de San José: Estudios y Publicaciones Alforja.

KyMLiCKA, W. y NORMAn, W. (1996). El retorno del ciudadano. Una revisión de la producción reciente en teoría de la ciudadanía. Versión en castellano. Cuadernos del Claeh, (75), 81-112.

LECHNER, N. (1997). Cultura política y gobernabilidad democrática. Leviatán: Revista de hechos e ideas, (68), 75-86.

Mallimaci, F. (2006). Historia de vida y métodos biográficos. En I. VASILACHIS (coord.), Estrategias de investigación cualitativa. Barcelona: Gedisa.

MARTínEZ, J. (2008). Participación política juvenil como políticas del acontecimiento. Revista Argentina de Sociología, (11), 148-168.

Mouffe, C. (1999). El retorno de lo político. Comunidad, ciudadanía, pluralismo, democracia radical. Barcelona: Paidós.

OCAMPO, A. (2011). Ciudadanía juvenil, juventud y Estado: Discursos de gobierno sobre sus significados. Revista Latinoamericana de Ciencias Sociales, Niñez y Juventud, 9(1), 287-303.

Pateman, C. (1996). Críticas feministas a la dicotomía público/privado. En C. Castells (ed.), Perspectivas feministas en teoría política. Barcelona: Paidós.

Patiño, J., Alvarado, S. y Ospina, M. (2014). Ampliación de sentidos sobre las prácticas políticas de jóvenes con vinculación a siete movimientos 
sociales en Colombia. Revista Latinoamericana de Ciencias Sociales, Niñez y Juventud, 12(1), 257-275.

PÉREZ, L. (2011). Ciudadanía y Definiciones. Cuadernos de Filosofía del Derecho, 177-221.

Reguillo, R. (2003). Ciudadanías Juveniles en América Latina. Última Década, (19), 11-30.

RodrígueZ, A. (2017). Reflexiones sobre el concepto cultura política y la investigación histórica de la democracia en América Latina. Historia y Memoria, (14),

205-247. http://dx.doi.org/10.19053/20275137.n14.2017.5820

VARÓN, D. (2014). La ciudadanía juvenil y los mecanismos de participación en jóvenes: El Estatuto de Ciudadanía Juvenil (Ley 1622 de 2013) y la construcción de la realidad desde el derecho. Verba Iuris, (31), 115-134.

VÁZQUEZ, C. (2011). La participación ciudadana juvenil como un recurso externo al Gobierno. Revista Latinoamericana de Ciencias Sociales, Niñez y Juventud, 9(1), 45-59.

Vecina, C. (2016). Promoviendo la participación juvenil desde la comunidad. Trabajo Social Global. Revista de Investigaciones en Intervención social, 11(6), 121-142. 